\title{
Compact WLAN Monopole Antenna with L-shaped Strip Line and Spiral Line Loaded Ring Resonator
}

\author{
Merih Palandöken*, Cem Baytöre, Adnan Kaya \\ Izmir Katip Celebi University \\ Cigli, Izmir, Turkey \\ *merih.palandoken@ikc.edu.tr
}

\begin{abstract}
In this paper, a compact monopole microstrip antenna is presented for dual-band WLAN mobile modules operating in 2.4GHz and $5.2 \mathrm{GHz}$ bands. The proposed antenna design is based on direct connection of two separate microstrip resonators, one of which is in the form of spiral resonator loaded ring resonator while the other resonator is the conventional $\lambda / 4 \mathrm{~L}$-shaped strip resonator. The overall size of the antenna is $0.08 \lambda_{0} \times 0.16 \lambda_{0}$ at $2.4 \mathrm{GHz}$ resonance frequency. The reflection coefficient, S11 of the antenna is smaller than $10 \mathrm{~dB}$ between $2.37 \mathrm{GHz}$ and $2.43 \mathrm{GHz}$ with $60 \mathrm{MHz}$ bandwidth in the lower frequency band, and between $5.01 \mathrm{GHz}$ and $5.41 \mathrm{GHz}$ with $400 \mathrm{MHz}$ bandwidth in the higher frequency band. The radiation efficiencies are $46 \%$ and $95 \%$ at $2.4 \mathrm{GHz}$ and $5.2 \mathrm{GHz}$, respectively with the omnidirectional radiation pattern. The proposed antenna can be integrated into compact wireless modules operating $2.4 \mathrm{GHz}$ and 5.2 GHz WLAN bands.
\end{abstract}

Keywords: WLAN compact antenna, spiral resonator, L-shaped strip resonator, ring resonator

\section{Introduction}

The current technological trend in wireless communication applications concerning mobile wireless devices imposes the design requirement of compact antennas with planar resonator geometries in low-profile form for low-cost manufacturing and high integrability with printed circuit boards. On the other hand, the dual-band operability of the compact antennas within the allocated bandwidths has become a common sense for high speed data transmission enabling multifunctional services in one electronic device. The customer demands in wireless services for diverse WLAN applications have initiated different antenna structures to be designed with low-profile, light weight, flush mounted to fit into the limited physical space of portable components. Several antenna types with compatible operability to WLAN standard requirements have been developed [1-17]. In the class of well-known microstrip antennas, the planar monopole antennas have especially received much more interest than other antenna types due to their potentials satisfying desired radiation properties of dual band or multiband, wide bandwidth, and low profile for a wireless communication system[1-13]. Artificial material based antenna design is one of emerging compact microstrip antenna design methods for desired antenna radiation performance in a limited volume [14-19].

In this paper, a compact dual-band WLAN antenna composed of two strip line resonators in the form of spiral resonator loaded ring resonator and an L-shaped resonator is proposed for dual band operation. To decrease the antenna physical length, $\lambda / 2$ resonance at the lower frequency is excited in a resonator configuration composed of ring and spiral resonators. The higher resonance is excited in an L-shaped resonator in the form of $\lambda / 4$ resonance. The higher resonance frequency can be adjusted in an independent manner from the lower resonance frequency, which increases the design flexibility of operating bands. These two resonators are directly connected to an asymmetric feeding line. Due to the application possibility of using the proposed antenna in wireless modules, one side of the substrate is structured while remaining the other side unmetallized.

The paper is organized in the following manner. In Section II, the design principle of the proposed antenna is explained with the geometric parameters. In Section III, the numerical calculations of the reflection parameter is illustrated with the surface current distributions at the resonance frequencies to explain the antenna operation principle. The radiation patterns at the lower and higher frequency bands are also shown at three orthogonal planes.

\section{Antenna Design}


The proposed compact dual-band WLAN antenna is shown in Figure 1. The geometric parameters of the antenna are tabulated in Table 1.
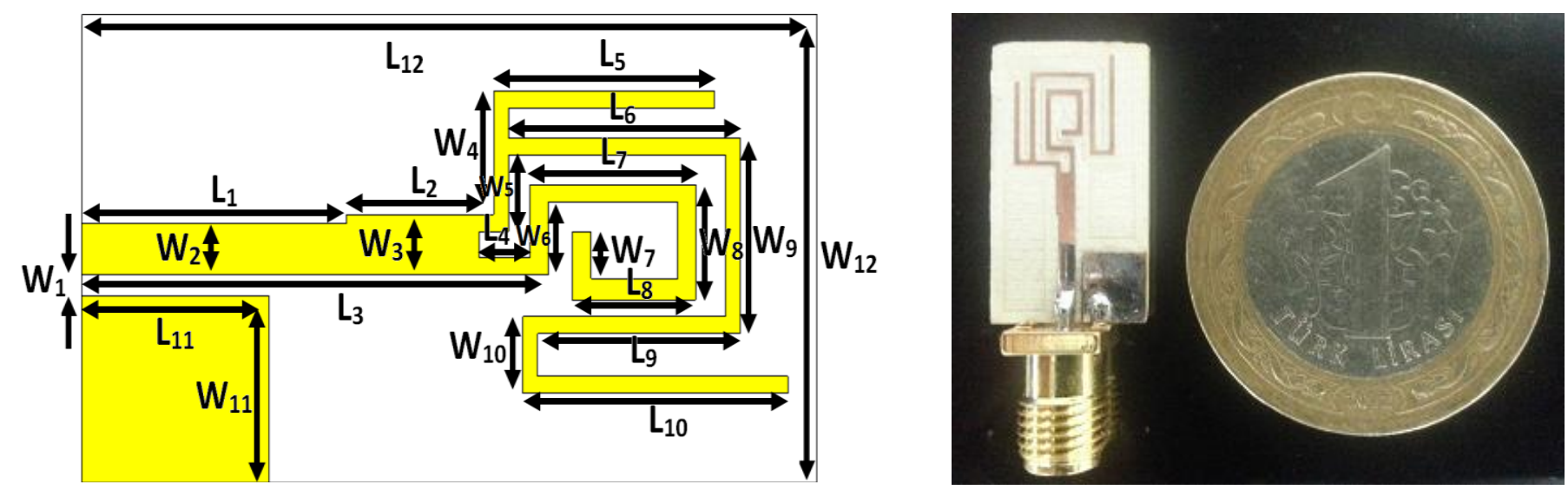

Fig. 1: The proposed compact dual-band WLAN antenna design.

Table 1: Antenna Geometric Parameters.

\begin{tabular}{|l|l|l|l|}
\hline $\mathrm{L}_{1}=7.20$ & $\mathrm{~L}_{2}=4.00$ & $\mathrm{~L}_{3}=12.7$ & $\mathrm{~L}_{4}=1.40$ \\
\hline $\mathrm{L}_{5}=6.00$ & $\mathrm{~L}_{6}=6.30$ & $\mathrm{~L}_{7}=4.50$ & $\mathrm{~L}_{8}=3.34$ \\
\hline $\mathrm{L}_{9}=5.50$ & $\mathrm{~L}_{10}=7.20$ & $\mathrm{~L}_{11}=5.10$ & $\mathrm{~L}_{12}=20.0$ \\
\hline $\mathrm{W}_{1}=0.50$ & $\mathrm{~W}_{2}=1.20$ & $\mathrm{~W}_{3}=1.40$ & $\mathrm{~W}_{4}=2.90$ \\
\hline $\mathrm{W}_{5}=1.80$ & $\mathrm{~W}_{6}=1.70$ & $\mathrm{~W}_{7}=1.10$ & $\mathrm{~W}_{8}=2.68$ \\
\hline $\mathrm{W}_{9}=4.60$ & $\mathrm{~W}_{10}=1.80$ & $\mathrm{~W}_{11}=4.40$ & $\mathrm{~W}_{12}=11.0$ \\
\hline
\end{tabular}

The proposed WLAN monopole antenna is basically composed of two microstrip line resonators on the top of $1.52 \mathrm{~mm}$ thick FR4 substrate with the material parameters of relative permittivity 4.4 and loss tangent 0.02 . These resonators are directly connected to the feeding line in the form of an asymmetric coplanar transmission line to have more efficient field coupling through the galvanic connection. The proposed antenna has the overall size of $0.08 \lambda_{0} \times 0.16 \lambda_{0}$ at the lower resonance frequency.

The physical parameters of L-shaped resonator are determined to have $\lambda_{0} / 4$ resonance at the higher frequency band. The resonance current distribution at the lower frequency band is due to $\lambda_{0} / 2$ resonance excitation of the combination of ring and spiral resonators. In other words, the electrical length of the ring resonator is increased with the additional spiral resonator. The important point in the design is to determine at which part of the resonator has to be directly connected to the feeding line. The ground plane size and feeding line length are optimized for best return loss in two frequency bands due to the impedance transformation feature of feeding line and ground plane.

\section{Numerical Computation Results}

The return loss of the compact WLAN antenna is numerically calculated with commercial 3D FEM based electromagnetic field simulator HFSS. The reflection parameter is shown in Figure 2. 

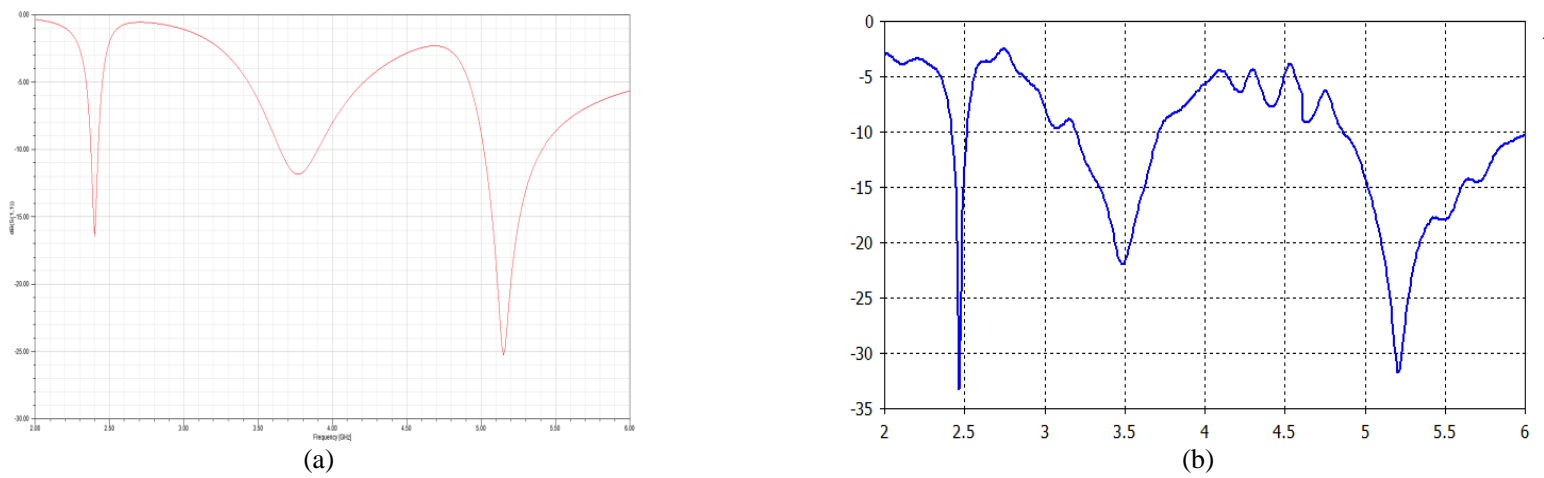

Fig. 2: (a) Simulated and (b) measured reflection parameter of compact dual-band WLAN antenna.

The antenna return loss is better than $10 \mathrm{~dB}$ in the lower frequency band between $2.37 \mathrm{GHz}$ and $2.43 \mathrm{GHz}$ with the maximum value of $16.46 \mathrm{~dB}$ at $2.4 \mathrm{GHz}$, and in the higher frequency band between $5.01 \mathrm{GHz}$ and $5.41 \mathrm{GHz}$ with the maximum value of $25 \mathrm{~dB}$ at $5.15 \mathrm{GHz}$.

The surface current distributions at two resonant frequencies are shown in Figure 3, which indicates the main operation principle of the antenna.

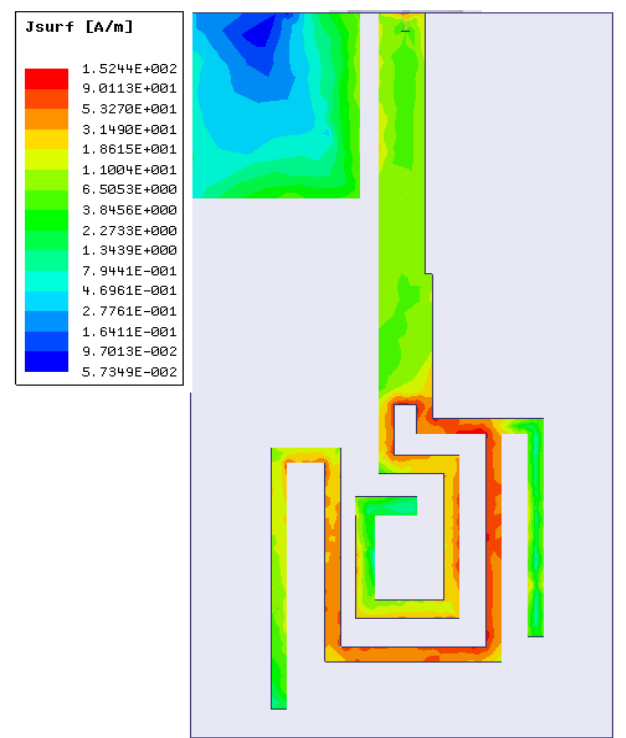

(a)

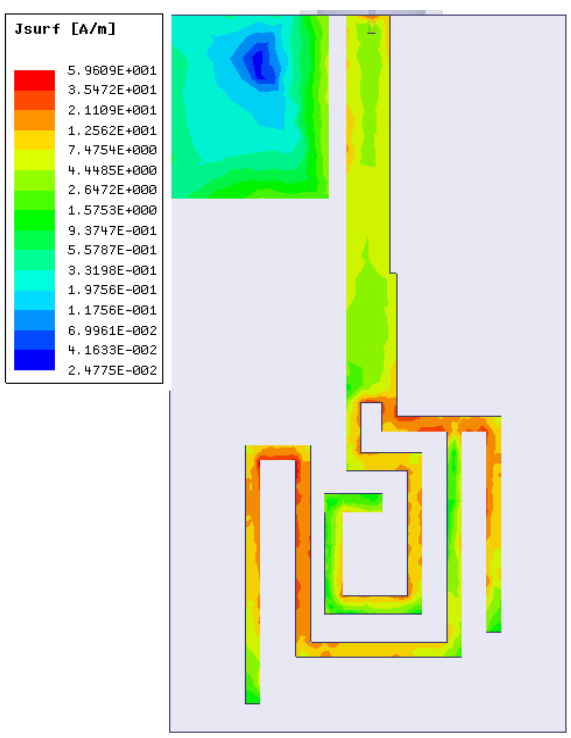

(b)

Fig. 3: Surface current distribution at (a) $2.4 \mathrm{GHz}$ and (b)5.2GHz.

As it can be deduced from Figure 3, the surface current distribution at $2.4 \mathrm{GHz}$ is in the form of $\lambda / 2$ resonance current distribution in the spiral and ring resonator combination. At $5.2 \mathrm{GHz}$, the surface current on L-shaped strip resonator has a similar form of $\lambda / 4$ resonant current distribution with the excitation of adjacent ring resonator in $\lambda$ resonance mode. This is an expected consequence of $\lambda / 4$ impedance transformation of open-circuited line into a short circuited line, which increases the surface current at the short circuited location. The resonant excitation of L-shaped resonator has a quite minor effect on the resonance frequency in the lower band due to the field resemblance of the resonance current distributions of spiral resonator loaded ring resonator at $2.4 \mathrm{GHz}$ and $5.2 \mathrm{GHz}$ at the antenna foot-point. It can be implied that any type of resonator geometry, designed for the higher frequency operation, which has no effect on the resonant current distribution in the lower frequency band results into the resonator decoupling. This simplifies the resonance frequency tuning of the antenna for the dual-band operation due to the independent geometric modification of decoupled resonator geometries. The normalized radiation patterns for the co- and cross-polarizations are shown in Figure 4 for each of three orthogonal planes. 


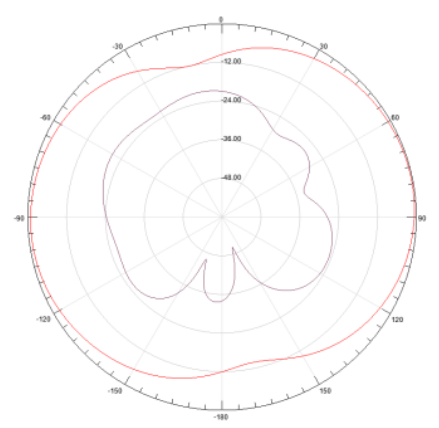

xy-plane at $2.4 \mathrm{GHz}$

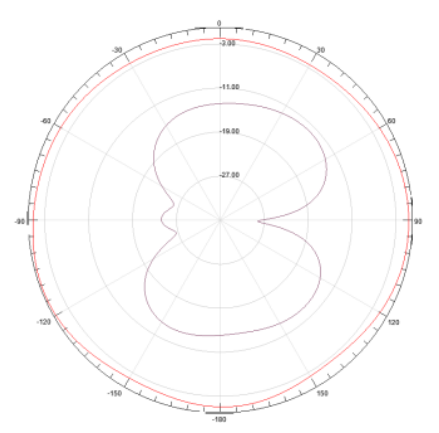

xz-plane at $2.4 \mathrm{GHz}$

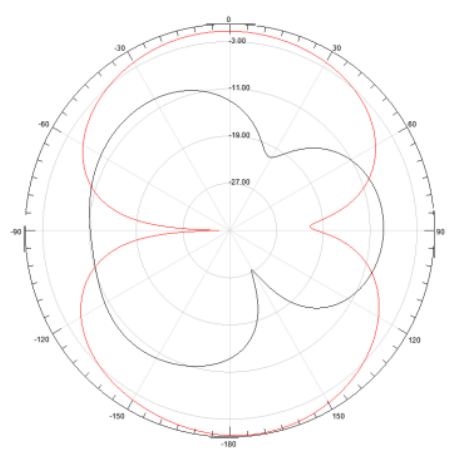

xy-plane at $2.4 \mathrm{GHz}$

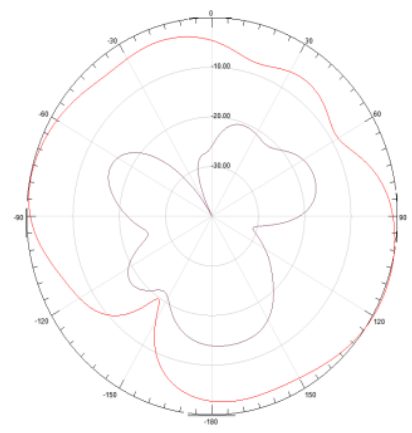

xy-plane at $5.2 \mathrm{GHz}$

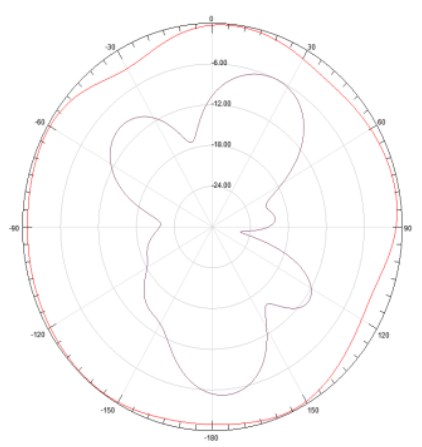

xz-plane at $5.2 \mathrm{GHz}$

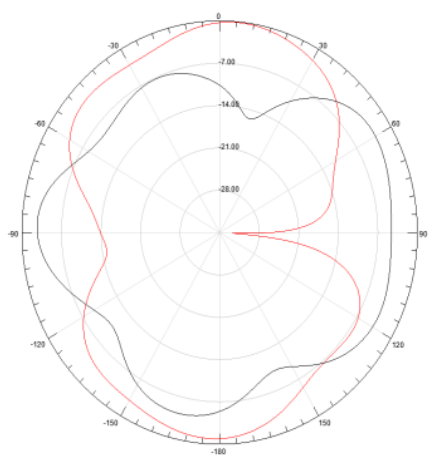

xz-plane at $5.2 \mathrm{GHz}$

Fig. 4: Normalized co- and cross-polarization radiation patterns on $x y, y z$ and $x z$ planes at $2.4 \mathrm{GHz}$ and 5.2GHz.

As shown in Figure 4, the radiation patterns are quite similar to the omnidirectional radiation patterns on xy and yz planes at $2.4 \mathrm{GHz}$ with maximum $-24 \mathrm{~dB}$ cross polarization level in the main beam direction. The radiation patterns at $5.2 \mathrm{GHz}$ have higher cross polarization levels at $\mathrm{xy}$ and yz planes in comparison to the radiation patterns on the same planes at 2.4GHz. However, the signal reception in dual frequency bands is accomplished with permissible co-polarization level of better than $-13 \mathrm{~dB}$ in the main beam direction at both planes. The radiation efficiencies are $46 \%$ and $95 \%$ at $2.4 \mathrm{GHz}$ and $5.2 \mathrm{GHz}$, respectively.

\section{Antenna Performance Comparison}

The proposed WLAN antenna has been compared with three modified versions of a WLAN antenna composed of monopole and loop strips designed to be mounted along the hinge of the ultrabook computer for dual-band operation[12]. The design principle of the reference antenna is based on the use of grounded loop strip for $\lambda / 2$ resonance and open-ended monopole strip for the wideband $\lambda / 4$ resonance mode to excite for dual-band operation with the effect of electrically large metal ground plane of ultrabook computer. Because the reference antenna has been designed to operate within the top and bottom metal covers of ultrabook computer, the original form of the reference antenna has been modified into three new 
versions in order for the current design to be used in free space applications. The resulting additional three versions suitable for the operation without metal housing effects of ultrabook computer are shown in Figure 5 with antenna radiation parameters tabulated in Table 2 .

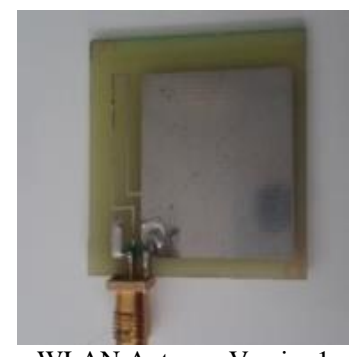

WLAN Antenna Version1

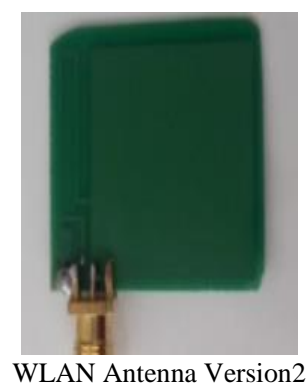

WLAN Antenna Version2

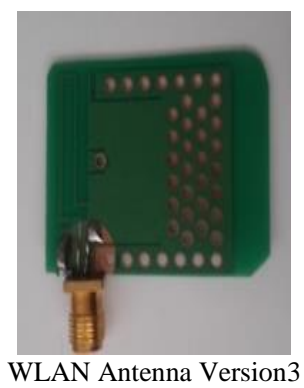

WLAN Antenna Version3

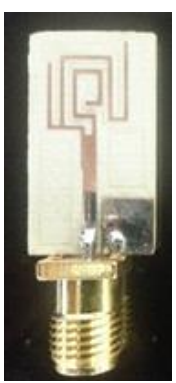

Fig. 5: Three versions of reference antenna and proposed compact WLAN antenna.

Table 2: Antenna Geometric Parameters.

\begin{tabular}{|c|c|c|c|c|}
\hline & WLAN-1 & $W L A N-2$ & $W L A N-3$ & $\begin{array}{c}\text { Current Antenna } \\
\text { Design }\end{array}$ \\
\hline $\begin{array}{c}-10 \mathrm{~dB} \\
\text { bandwidth }\end{array}$ & $\begin{array}{c}110 \mathrm{MHz} \\
(2.34 \mathrm{GHz}-2.45 \mathrm{GHz}) \\
600 \mathrm{MHz} \\
(4.74 \mathrm{GHz}-5.34 \mathrm{GHz})\end{array}$ & $\begin{array}{c}130 \mathrm{MHz} \\
(2.47 \mathrm{GHz}-2.60 \mathrm{GHz}) \\
570 \mathrm{MHz} \\
(5.08 \mathrm{GHz}-5.65 \mathrm{GHz})\end{array}$ & $\begin{array}{c}\mathrm{S} 11 \\
(-8.74 \mathrm{~dB} \text { at } 2.47 \mathrm{GHz} \\
-8.58 \mathrm{~dB} \text { at } 5.79 \mathrm{GHz}) \\
\text { unmatched }\end{array}$ & $\begin{array}{c}60 \mathrm{MHz} \\
(2.37 \mathrm{GHz}-2.43 \mathrm{GHz}) \\
400 \mathrm{MHz} \\
(5.01 \mathrm{GHz}-5.41 \mathrm{GHz})\end{array}$ \\
\hline $\begin{array}{l}\text { Radiation } \\
\text { Efficiency }\end{array}$ & $\begin{array}{l}77 \% \text { at } 2.4 \mathrm{GHz} \\
93 \% \text { at } 5.3 \mathrm{GHz}\end{array}$ & $\begin{array}{l}93 \% \text { at } 2.4 \mathrm{GHz} \\
94 \% \text { at } 5.4 \mathrm{GHz}\end{array}$ & $\begin{array}{l}81 \% \text { at } 2.4 \mathrm{GHz} \\
81 \% \text { at } 5.8 \mathrm{GHz}\end{array}$ & $\begin{array}{l}46 \% \text { at } 2.4 \mathrm{GHz} \\
95 \% \text { at } 5.2 \mathrm{GHz}\end{array}$ \\
\hline Directivity & $\begin{array}{l}1.85 \mathrm{dBi} \text { at } 2.4 \mathrm{GHz} \\
3.88 \mathrm{dBi} \text { at } 5.3 \mathrm{GHz}\end{array}$ & $\begin{array}{l}2.08 \mathrm{dBi} \text { at } 2.4 \mathrm{GHz} \\
3.75 \mathrm{dBi} \text { at } 5.4 \mathrm{GHz}\end{array}$ & $\begin{array}{l}1.66 \mathrm{dBi} \text { at } 2.4 \mathrm{GHz} \\
4.69 \mathrm{dBi} \text { at } 5.8 \mathrm{GHz}\end{array}$ & $\begin{array}{l}2.43 \mathrm{dBi} \text { at } 2.4 \mathrm{GHz} \\
3.76 \mathrm{dBi} \text { at } 5.2 \mathrm{GHz}\end{array}$ \\
\hline Gain & $\begin{array}{l}0.73 \mathrm{dBi} \text { at } 2.4 \mathrm{GHz} \\
3.58 \mathrm{dBi} \text { at } 5.3 \mathrm{GHz}\end{array}$ & $\begin{array}{l}1.78 \mathrm{dBi} \text { at } 2.4 \mathrm{GHz} \\
3.5 \mathrm{dBi} \text { at } 5.4 \mathrm{GHz}\end{array}$ & $\begin{array}{l}0.58 \mathrm{dBi} \text { at } 2.4 \mathrm{GHz} \\
3.78 \mathrm{dBi} \text { at } 5.8 \mathrm{GHz}\end{array}$ & $\begin{array}{l}-0.96 \mathrm{dBi} \text { at } 2.4 \mathrm{GHz} \\
3.57 \mathrm{dBi} \text { at } 5.2 \mathrm{GHz}\end{array}$ \\
\hline $\begin{array}{c}\text { Antenna } \\
\text { size }\end{array}$ & $0 \lambda 216 \lambda_{9} \times 0.236 .0$ & $0 \lambda 216 \lambda_{9} \times 0.236 .0$ & $0 \lambda 216 \lambda_{0} \times 0 \lambda 180 \lambda_{0}$ & $0 \lambda 16 \lambda_{0} \times 0.08 \lambda_{0}$ \\
\hline
\end{tabular}

\section{Conclusion}

This paper presents the design and operation principles of a compact monopole microstrip antenna for dual-band WLAN operations in $2.4 \mathrm{GHz}$ and $5.2 \mathrm{GHz}$ bands. The antenna has $60 \mathrm{MHz}$ bandwidth between $2.37 \mathrm{GHz}$ and $2.43 \mathrm{GHz}$ in the lower frequency band, and $400 \mathrm{MHz}$ bandwidth between $5.01 \mathrm{GHz}$ and $5.41 \mathrm{GHz}$ in the higher frequency band. The radiation efficiencies are $46 \%$ and $95 \%$ at $2.4 \mathrm{GHz}$ and $5.2 \mathrm{GHz}$, respectively with an omnidirectional radiation pattern at two orthogonal planes. The proposed monopole WLAN antenna has been compared with three new versions of a reference antenna in terms of antenna parameters in addition to antenna compactness. The antenna is electrically small with the overall size of 0.08 . $0 \mathrm{X}$ $0 \lambda 16 \lambda_{\theta}$ at $2.4 \mathrm{GHz}$ resonance frequency, which is at most $33 \%$ of three benchmarking antennas. The proposed antenna has lowest gain and radiation efficiency at the lower frequency with the highest directivity. The low gain at the lower frequency can be enhanced in $3 \mathrm{dBi}$ with the result of gain enhancement in the higher frequency band by the use of the proposed radiator geometry in $2 \times 1$ antenna array form, which results the proposed antenna even more compact than the other remaining three versions of the reference antenna. Therefore, the proposed antenna has a technical potential to be used in the transceiver modules of compact wireless devices operating in WLAN bands.

\section{Acknowledgements} Turkey).

This work has been supported by the Project 114E078 of TUBITAK (scientific and technological research council of 


\section{References}

[1] J. K. Pakkathillam and M. Kanagasabai, "Performance evaluation of a dualband paper substrate wireless sensor networks antenna over curvilinear surfaces," IET Microwaves, Antennas \& Propagation, vol. 9, pp. 715-722, 2015.

[2] M. Moosazadeh and S. Kharkovsky, "Compact and Small Planar Monopole Antenna with Symmetrical L- and UShaped Slots for WLAN/WiMAX Applications," IEEE Antennas and Wireless Propagation Letters, vol. 13, pp. 388391, 2014.

[3] W. S. Kim, S. Choi, and G. TJ Jeong, "A Low-Profile WLAN Antenna with Inductor and Tuning Stub for Broadband Impedance Matching," International Journal of Antennas and Propagation, pp. 6, 2014.

[4] H. Chen, X. Yang, Y. Z. Yin, S. T. Fan, and J. J. Wu, "Triband Planar Monopole Antenna with Compact Radiator for WLAN/WiMAX Applications," IEEE Antennas and Wireless Propagation Letters, vol. 12, pp. 1440-1443, 2013.

[5] X. Zhou, X. L. Quan, and R. L. Li, "A Dual-Broadband MIMO Antenna System for GSM/UMTS/LTE and WLAN Handsets," IEEE Antennas and Wireless Propagation Letters, vol. 11, pp. 551-554, 2012.

[6] X. M. Ling and R. L. Li, "A Novel Dual-Band MIMO Antenna Array With Low Mutual 1 Coupling for Portable Wireless Devices," IEEE Antennas and Wireless Propagation Letters, vol. 10, pp. 1039-1042, 2011.

[7] Q. Luo, J. R. Pereira, and H. M. Salgado, "Compact Printed Monopole Antenna With Chip Inductor for WLAN," IEEE Antennas and Wireless Propagation Letters, vol. 10, pp. 880-883, 2011.

[8] J. Zhang, J. O. Yang, K. Z. Zhang, and F. Yang, "A Novel Dual-Band MIMO Antenna with Lower Correlation Coefficient," International Journal of Antennas and Propagation, pp. 7, 2012.

[9] J. H. Yoon and Y. C. Rlee, "Design of a microstrip-fed monopole antenna with a rectangular slit ground and a rectangular projection strip for dual-band WLAN operations," Microwave and Optical Technology Letters, vol. 54, pp. 1039-1044, 2012.

[10] A. Mehdipour, A. R. Sebak, C. W. Trueman, and T. A. Denidni, "Compact Multiband Planar Antenna for 2.4/3.5/5.2/ 5.8-GHz Wireless Applications," IEEE Antennas and Wireless 14 Propagation Letters, vol. 11, pp. 144-147, 2012.

[11] J. Pei, A.G. Wang, S. Gao, and W. Leng, "Miniaturized Triple-Band Antenna With a Defected Ground Plane for WLAN/WiMAX Applications," IEEE Antennas and Wireless 17 Propagation Letters, vol. 10, pp. 298-301, 2011.

[12] L. Y. Chen and K. L. Wong, "2.4/5.2/5.8 GHz WLAN antenna for the ultrabook computer with metal housing," AsiaPacific Microwave Conference Proceedings (APMC), pp. 322-324, 2012.

[13] C. C. Yu, J. H. Yang, and C. C. Chen, "Hsieh WC. A Compact Printed Multi-band Antenna for Laptop Applications," PIERS Online, vol. 7, pp. 605-608, 2011.

[14] J. Zhu, M. A. Antoniades, and G. V. Eleftheriades, "A Compact Tri-Band Monopole Antenna with Single-Cell Metamaterial Loading," IEEE Transactions on Antennas and Propagation, vol. 58, pp. 1031-1038, 2010.

[15] H. Huang, Y. Liu, S. Zhang, and S. Gong, "Multiband Metamaterial-Loaded Monopole Antenna for WLAN/WiMAX Applications," IEEE Antennas and Wireless Propagation Letters, vol. 14, pp. 662-665, 2015.

[16] P. Liu, Y. Zou, B. Xie, X. Liu, and B. Sun, "Compact CPW-Fed Tri-Band Printed Antenna With Meandering SplitRing Slot for WLAN/WiMAX Applications," IEEE Antennas and Wireless Propagation Letters, vol. 11, pp. 12421244, 2012.

[17] M. Palandoken, A. Grede, and H. Henke, "Broadband Microstrip Antenna with Left- Handed Metamaterials," IEEE Transactions on Antennas and Propagation, vol. 57, pp. 331-7338, 2009.

[18] T. K. Upadhyaya, S. P. Kosta, R. Jyoti, and M. Palandoken, "Negative refractive index material inspired 90deg electrically tilted ultra-wideband resonator," Optical Engineering, vol. 53, no. 10, 2014.

[19] T. K. Upadhyaya, S. P. Kosta, R. Jyoti, and M. Palandöken, "Novel stacked $\mu$-negative material-loaded antenna for satellite applications," International Journal of Microwave and Wireless Technologies, vol. 8, no. 2, pp. 229 - 235 , 2016. 